Chapman University

Chapman University Digital Commons

Psychology Faculty Articles and Research

Psychology

$10-11-2019$

\title{
Self-Concept Clarity and the Bodily Self: Malleability Across Modalities
}

\author{
Sonia A. Krol \\ McGill University \\ Rémi Thériault \\ McGill University \\ Jay A. Olson \\ McGill University \\ Amir Raz \\ Chapman University, raz@chapman.edu \\ Jennifer A. Bartz \\ McGill University
}

Follow this and additional works at: https://digitalcommons.chapman.edu/psychology_articles

Part of the Cognition and Perception Commons, Cognitive Psychology Commons, Other Psychology Commons, and the Personality and Social Contexts Commons

\section{Recommended Citation}

Krol, S. A., Thériault, R., Olson, J. A., Raz, A., \& Bartz, J. A. (2020). Self-concept clarity and the bodily self: Malleability across modalities. Personality and Social Psychology Bulletin, 46(5), 808-820. https://doi.org/ $10.1177 / 0146167219879126$

This Article is brought to you for free and open access by the Psychology at Chapman University Digital Commons. It has been accepted for inclusion in Psychology Faculty Articles and Research by an authorized administrator of Chapman University Digital Commons. For more information, please contact laughtin@chapman.edu. 


\section{Self-Concept Clarity and the Bodily Self: Malleability Across Modalities}

\section{Comments}

This is a pre-copy-editing, author-produced PDF of an article accepted for publication in Personality and Social Psychology Bulletin, volume 46, issue 5, in 2020 following peer review. The definitive publisherauthenticated version is available online at https://doi.org/10.1177/0146167219879126.

\section{Copyright}

The authors 


\section{Self-Concept Clarity and the Bodily Self:}

\section{Malleability Across Modalities}

Sonia A. Krol ${ }^{1}$, Rémi Thériault ${ }^{2,3}$, Jay A. Olson², Amir Raz ${ }^{1,2,3,4}$, \& Jennifer A. Bartz ${ }^{1 *}$

${ }^{1}$ Department of Psychology, McGill University, 2001 McGill College, Montreal, Quebec, Canada, H3A 1G1

${ }^{2}$ Department of Psychiatry, McGill University, 1033 Pine Avenue West, Montreal, Quebec, Canada, H3A 1A1

${ }^{3}$ Institute for Interdisciplinary Behavioral and Brain Sciences, Chapman University, Irvine, CA, 92618, USA

${ }^{4}$ The Lady Davis Institute for Medical Research, Jewish General Hospital, 3755 Cote Ste. Catherine, Montréal, QC, H3T 1E2, Canada

*Corresponding author: Jennifer A. Bartz, Department of Psychology, McGill University, 2001 Avenue McGill College, Montreal, Quebec, Canada, H3A 1G1; Phone: (514) 398-7626;

Fax: (514) 398-4896; Email: jennifer.bartz@mcgill.ca. 


\begin{abstract}
The self has fascinated scholars for centuries. Although theory suggests that the selfconcept (cognitive self-understanding) and bodily self (pre-reflective awareness of one’s body) are related, little work has examined this notion. To this end, in Study 1, participants reported on self-concept clarity (SCC) and completed the Rubber Hand Illusion (RHI), a paradigm in which synchronous (versus asynchronous) stimulation between a prosthetic hand and one's own hand leads one to "embody" the prosthetic hand. Whereas participants were equally susceptible to the RHI during synchronous stroking, low SCC individuals were more vulnerable to the illusion during asynchronous stroking, when the effect is unwarranted. Conceptually replicating and extending this finding, in Study 2, low SCC individuals were more susceptible to the body-swap illusion - the impression that another person's body is one’s own. These findings suggest that a clear sense of self implies clarity and stability of both the self-concept and the bodily self.
\end{abstract}

Keywords: self, self-concept, rubber hand illusion, multisensory integration processes 
Self-Concept Clarity and the Bodily Self:

\section{Malleability Across Modalities}

Where does our sense of self come from? How do we maintain a clear and stable sense of self? Beginning with William James (1890), philosophers and psychologists have defined and studied the self in different ways to understand these fundamental questions (Gallagher, 2000; Neisser, 1997). Personality and social psychologists have largely focused on the self-concept. Essentially, the self-concept—-the cognitive generalization of one's self-knowledge and selfbeliefs based on past experiences_encompasses everything that an individual claims as “me” or “mine”: personality attributes, values, attitudes, beliefs, preferences, goals, emotional states, social roles, and even physical appearance (Markus, 1977). Researchers conceptualizing the self in this way have shown that people are generally motivated to maintain a stable self-concept: that is, people are resistant to information that is incongruent with their self-views and often reject

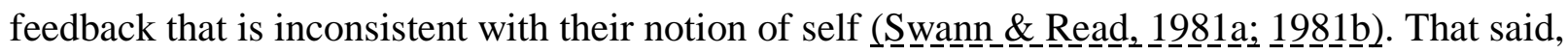
it is also well-established that the self-concept is dynamic and subject to change, especially in response to changes in the social environment or social roles (Markus \& Wurf, 1987). For example, research indicates that the self-concept is likely to change during life transitions, such as going to university or becoming a parent (Kling, Ryff, \& Essex, 1997), or in close relationships, as people readily incorporate close others into their sense of self (e.g., Aron, Aron, Tudor, \& Nelson, 1991; Mashek, Aron, \& Boncimino, 2003). In the face of these changes, it is thought that the self-concept integrates new information and experiences with existing selfknowledge allowing individuals to organize the new and old together to maintain a consistent and stable sense of self (Markus, 1977). 
Individuals, of course, vary in their ability to establish a consistent and stable sense of self; such variability has been conceptualized as self-concept clarity (SCC)-i.e., the extent to which the self-concept is clearly and confidently defined, internally consistent, and temporally stable (Campbell et al., 1996). Over two decades of research has established the internal, external, and discriminant validity of SCC (Lodi-Smith \& DeMarree, 2017). For example, individuals with lower self-reported SCC show lower levels of self-other agreement in personality ratings and lower accuracy in predicting their own behaviour, suggesting that they "know" themselves less well than do those who report higher SCC (Lewandowski \& Nardone, 2012). In addition to having a less clear and confidently-defined self-concept, individuals with low SCC are characterized by a less stable and more malleable self-concept. It is thought that with no clear "self" to draw upon, these individuals are more prone to incorporating new, and potentially conflicting, information into their self-understanding. Supporting this idea, Cuperman and colleagues (2014) showed that people with a weak sense of self were more likely to accept false, generic personality descriptions as characteristic of the self, and they were more prone to temporarily taking on the personality characteristics of a stranger following a brief interaction. Similarly, Smeesters et al. (2009) found that individuals with less accessible self-knowledge (presumably related to having a weak and unclear self-concept) were more susceptible to priming effects than individuals with highly accessible self-knowledge. Taken together, these findings suggest that those with low SCC are characterized by more malleable cognitive self representations.

While personality and social psychologists have focused on the self-concept, for decades, cognitive psychologists and philosophers of mind have addressed questions about the self by studying the bodily self, also known as "bodily self-consciousness” (e..g.__Lengengennh_- 


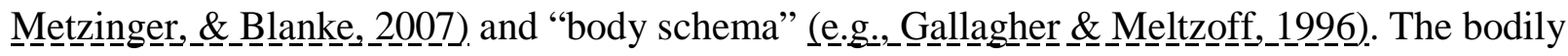
self can be defined as the implicit, pre-reflective awareness of the perceptual experiences of

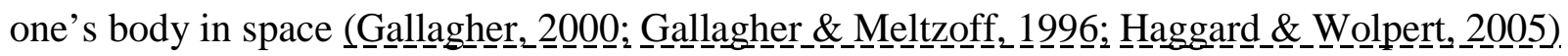
and is thought to rely on multisensory integration processes that are responsible for assimilating various sensory signals (e.g., visual, vestibular, auditory, tactile, proprioceptive) and resolving conflicts to generate a coherent representation of the body (Ehrsson, 2012; Kilteni, Maselli,

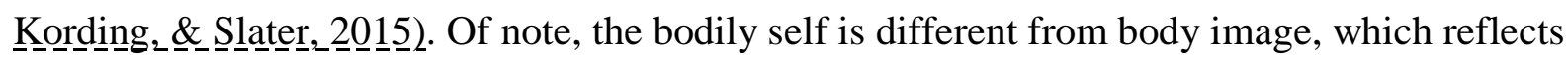
the conscious perceptions, attitudes, and beliefs one has about one’s body (Gallagher \& $\&$ Meltzoff, 1996). Importantly, the bodily self is thought to come online earlier in development than the self-concept. Developmental studies show that newborns less than an hour old can imitate facial gestures (e.g._._Meltzoff \& Moore,_19833), an ability thought to rely on the presence of a representation of one’s body (Gallagher \& Meltzoff, 1996). By contrast, the self-concept is thought to emerge in the second year of life (Fonagy, Gergely, Jurist, \& Target, 2002). This sequential emergence of these two notions of self is in line with the long-held understanding that the bodily self serves as the foundation for the development of the self-concept. As Freud (1961, p. 26) noted, “the ego is first and foremost a bodily ego” and, similarly, as Baumeister (1992, p. 2) wrote, "everywhere in the world, self starts with body”. In sum, the self-concept and bodily self represents different perspectives on the self and research to date indicates that these two notions of self rely on different psychological processes and come online at different stages during development.

Intriguingly, as with the self-concept, our bodily self is somewhat malleable. The most famous and well-established empirical demonstration of this malleability is the Rubber Hand Illusion (RHI; Botvinick \& Cohen, 1998). In this illusion, participants are seated at a table with a 
life-like, prosthetic hand placed directly in front of them and with their own hand positioned on the table, next to the prosthetic hand, but hidden from view. The experimenter strokes both the visible prosthetic hand and the real hidden hand, using identical paintbrushes. Synchronous stroking between the prosthetic hand and a participant's hand causes the participant to experience the prosthetic hand as part of his or her own body (Botvinick \& Cohen, 1998; Longo, Schüür, Kammers, Tsakiris, \& Haggard, 2008). Interestingly, research indicates that the experience of “owning” the prosthetic changes the way participants’ own real hand is experienced. During the illusion, participants report feeling as if their real hand has “disappeared” (Longo et al., 2008), suggesting that the prosthetic hand has replaced the real hand in the body representation. Several studies have demonstrated that the RHI also induces a mislocalization of one's own real hand as being closer to the prosthetic hand than it really is (Abdulkarim \& Ehrsson, 2016; Botvinick_\&_Cohen, 1998; Tsakiris \& Remarkably, the RHI also induces physiological changes indicating that participants experience their real hand differently. Bending one of the prosthetic fingers backward (Armel \& Ramachandran, 2003) or stabbing a needle into it (Ehrssson et 2009) produces a heightened skin conductance response, indicative of autonomic reactivity, suggesting that participants are reacting as if their real hand were threatened. Taken together, psychological, behavioural and physiological evidence indicate that owning the prosthetic hand changes the way one's own real hand is experienced.

The RHI is thought to rely on the same multisensory integration processes responsible for generating the bodily self noted earlier. The illusion occurs as a result of the interaction between vision, touch, and proprioception (the sense of position of one's body parts) and the dominance of vision over proprioception. The vision of tactile stimulation on the prosthetic hand and the 
matching touch felt on the real hand become bound together in a single event; this then causes participants to misperceive the visible prosthetic hand as being part of their own body (Botvinick \& Cohen, 1998; Tsakiris, 2010). Indeed, these multisensory integration processes are so strong and automatic that the vast majority of participants report strongly experiencing the prosthetic hand as their own (Botvinick \& Cohen, 1998; Ehrsson, Spence, \& Passingham, 2004; Ehrsson, Holmes, \& Passingham, 2005; Lloyd, 2007). Importantly, though, asynchronous stroking — that is, when the prosthetic hand and the participant's own hand are stroked out of phase-typically elicits a weaker illusion or none at all since there is no sensory conflict between visual and tactile inputs to be resolved (Shimada, Fukuda, \& Hiraki, 2009; Tsakiris \& Haggard, 2005).

Recently, the malleability of the bodily self evidenced in the RHI has been extended to other bodily illusions using similar synchronous multisensory stimulation techniques. In the enfacement illusion, synchronous stroking between a participant's face and another person's face induces changes in self-recognition such that the other's facial features are incorporated into the participant’s own facial representation (Sforza, Bufalari, Haggard, \& Aglioti, 2010; TajaduraJiménez, Grehl, \& Tsakiris, 2012). Other work suggests that this malleability can be extended from individual body parts, like the hand and face, to the entire body. For example, out-of-body experiences can be induced by having participants observe a virtual avatar in front of them, outside of their personal space (i.e., third-person perspective), as it is stroked in synchrony with their own body (Lenggenhager, Tadi, Metzinger, \& Blanke, 2007; see Ehrssson,_2007 for

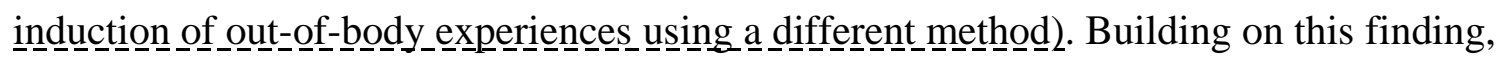
Petkova and Ehrsson (2008) were the first to induce illusory ownership over an actual person's body (i.e., not a virtual avatar): in the “body-swap” illusion, participants see another person’s body from the first-person perspective via a head-mounted display and are subjected to 
synchronized visuo-tactile stimulation with this person. This illusion, like the RHI, induces people to experience the other person's body as if it were their own. Indeed, this illusion is so robust that even standing across from and shaking hands with what appears to be one's own body (but is actually the other person's body) does not break the illusion (Petkova \& Ehrsson, 2008).

Taken together, the psychological self-concept and bodily self offer two approaches to understanding the self. Although clearly different from one another, theory suggests that these two notions of self are related (Gallagher, 2000); to date, however, we know of only a few studies that have touched on this issue. In one study, Banakou, Groten, and Slater (2013) induced illusory body ownership of a virtual child which increased participants' endorsement of childlike, rather than adult-like, attributes. This study suggests that the content of the self-concept is

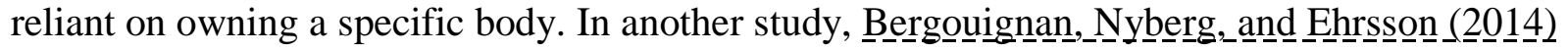
showed that disruption of the bodily self through the inducement of an out-of-body experience led to interference with encoding of episodic memories, a process critical for the formation and

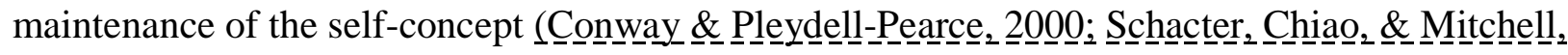
2003). Finally, Ainley, Maister, Brokfeld, Farmer, and Tsakiris (2013) showed that focusing attention on self-relevant aspects (e.g., hometown) improved awareness of internal bodily signals such as heartbeat. These studies provide initial evidence that the self-concept and bodily self are indeed related. As noted, one fundamental aspect of the self-concept is its relative clarity and stability (i.e., SCC). If the self-concept and the bodily self are related, then one would expect that malleability in the self-concept implies malleability in the bodily self. Such a finding would contribute to our understanding of the self by indicating that a clear and coherent sense of self entails clarity and coherence of both the self-concept and the bodily self. 
To this end, we conducted two studies to test whether individuals with a less clear, coherent, and stable self-concept are characterized by a more malleable bodily self. In Study 1, participants self-reported on their SCC and then underwent the RHI in which they experienced both synchronous and asynchronous visuo-tactile stimulation with a prosthetic hand. As noted, in the synchronous condition, multisensory integration processes are sufficiently strong and automatic that most people are susceptible to experiencing the illusion (Botvinick \& Cohen, 1998; Ehrsson, Spence, \& Passingham, 2004; Ehrsson, Holmes, \& Passingham, 2005; Lloyd, 2007). Thus, we predicted that overall participants would be more susceptible to "embodying” the prosthetic hand in the synchronous (vs. asynchronous) stroking conditions, as has been shown in prior work. However, we hypothesized that those low (vs. high) in SCC would be more susceptible to experiencing the illusion in the asynchronous stimulation condition, which typically does not elicit the illusion. Given that their sense of self is so tenuous and unclear, and that they are prone to incorporating any random, new information into their self-concept (Cuperman et al., 2014), we reasoned that individuals low in SCC would be more vulnerable to embodying the prosthetic hand even under inappropriate circumstances, when there is no sensory conflict to be resolved by multisensory integration. In Study 2, we aimed to conceptually replicate and extend our understanding of this effect by examining whether SCC is related to illusory body ownership using the body-swap illusion.

To assess malleability of the bodily self in Studies 1 and 2, we used the embodiment questionnaire (Longo et al., 2008), an instrument used to assess susceptibility to the RHI. Of note, although embodiment is often conceptualized as a unitary experience, research indicates that it can be broken down into three sub-components reflecting specific aspects of embodiment: ownership, location, and agency (Longo et al., 2008). We did not have a priori predictions about 
the relationship between SCC and these specific sub-components so we report our findings using the full scale. However, for the interested reader, we conducted exploratory analyses with these sub-components as the dependent variable to assess whether the effects we report in Studies 1 and 2 are specific to certain aspects of the illusion; results from these exploratory analyses are detailed in the Supplementary Materials.

\section{Study 1}

\section{Methods}

\section{Participants}

We recruited 80 individuals (55 women, 1 whose gender was unreported) from the McGill University community to participate. Participants ranged in age from 18-34 years $(M=$ 23.04, $S D=3.76$ ). The procedures were approved by the McGill University Institutional Review Board and participants were compensated with either course credit or \$10/hour.

Our sample size was determined based on prior studies that have observed individual difference effects on susceptibility to the RHI with samples of approximately 70 participants

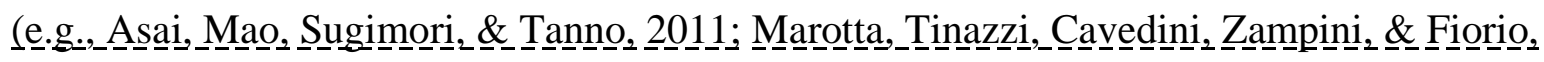
2016). We did not conduct an a priori power analysis; however, a post-hoc sensitivity power analysis indicated that our sample size of $N=80$ was sensitive to detect correlations of $r=.31$, representing a moderate effect (Cohen, 1988), with 80\% power.

\section{Procedure}

After giving informed consent, participants completed the Self-Concept Clarity scale (Campbell et al., 1996). They were then randomly assigned to either the synchronous or asynchronous condition of the RHI (condition order was counterbalanced). After the illusion, 
they completed the aforementioned questionnaire developed by Longo and colleagues (2008), which quantifies the subjective experience of the RHI. Approximately 20-mins later, after completing tasks unrelated to the current hypotheses, participants underwent the RHI again, with the alternate stroking style. Participants were debriefed upon completion of the study.

\section{Tasks and Measures}

Self-Concept Clarity scale (Campbell et al., 1996). This is a 12-item self-report measure of the extent to which one's self-concept is clearly and confidently defined, internally consistent, and stable. Participants indicate their agreement to each item using a five-point Likert scale ranging from "strongly disagree" (1) to "strongly agree” (5). The majority of the items are reverse coded, such as “My beliefs about myself often conflict with one another” and "My beliefs about myself seem to change very frequently”. After reverse coding, SCC is operationalized as the mean of all items, with higher numbers indicating greater SCC $(\omega=.91)$.

Rubber Hand Illusion (RHI; Botvinick \& Cohen, 1998). Participants sat in front of a table with their right hand, palm down, placed in front of them in a box frame. A realistic prosthetic hand was shown to the participants and then positioned approximately $15 \mathrm{~cm}$ to the left of the participant's own hand, outside of the box frame. Thus, the participant's hand was hidden from view while the prosthetic hand was visible. Given evidence that differences between the skin colour of the prosthetic hand and the participant's hand affect the strength of the RHI (Farmer, Tajadura-Jiménez, \& Tsakiris, 2012; Lira et al., 2017), we followed Kalckert and Ehrsson (2012) and covered both hands with a latex glove. Once the hands were in position, the experimenter sat in front of the participant and manually stimulated the visible prosthetic hand and the participant's unseen hand using two identical paintbrushes. Participants were stimulated on their second, third, and fourth fingers (index, middle, and ring fingers) from the proximal 
interphalangeal joint (second knuckle) to the tip of the finger, at a rate of approximately 1 stroke per second. The prosthetic hand was stimulated in the same manner, either in synchrony or asynchrony with the stimulation of the participant's hand. In the synchronous condition, the participant's hand and the rubber hand were stroked simultaneously in the same anatomical location with each stroke lasting approximately 1 second. In the asynchronous condition, the brush strokes on the participant's hand and prosthetic hand were temporally out of sync. Specifically, timing was delayed by approximately $500 \mathrm{~ms}$ such that a stroke was delivered to the real hand followed by a stroke to the prosthetic hand on the same anatomical location, but 500 ms later. In both conditions, participants were instructed to keep their own hand still and to focus on the prosthetic hand. Consistent with other work, stroking lasted for 2-mins in each condition (e.g., Asai, Mao, Sugimori, \& Tanno, 2011; Maister, Sebanz, Knoblich, \& Tsakiris, 2013; Tsakiris, Jiménez, \& Costantini, 2011).

Embodiment of the Rubber Hand Questionnaire (Longo et al., 2008). To assess the extent to which participants incorporated the prosthetic hand into their bodily self, we used the 10-item “embodiment of rubber hand” factor identified by Longo and colleagues (2008), which was previously used to quantify the subjective experience of the RHI (Bassolino et al., 2018; Grynberg \& Pollatos, 2015). Participants were asked to indicate the extent to which they agreed with each item, using a 7-point scale (1 = strongly disagree and $7=$ strongly agree $)$. Example items include: "During the experiment, there were times when it seemed like the rubber hand belonged to me" and "During the experiment, there were times when it seemed like the rubber hand was my hand” (see Table S1 for questionnaire). Consistent with other work (e.g., Tsakiris, 2010; Eshkevari, Rieger, Longo, Haggard, \& Treasure, 2012), degree of embodiment was operationalized as the mean of all items (synchronous: $\omega=.95$; asynchronous: $\omega=.93$ ). 


\section{Results and Discussion}

As noted, we hypothesized that overall participants would embody the prosthetic hand more in the synchronous (vs. asynchronous) stroking condition, but that those low (vs. high) in SCC would also be more susceptible to embodying the prosthetic hand in the asynchronous stimulation condition, which typically does not elicit the illusion, because their sense of self is so tenuous and unclear.

First, to verify that we successfully induced the illusion in the synchronous stroking condition, we compared the medians on two keys items of the embodiment questionnaire (items 4 and 8, see Table S1), following Kalckert and Ehrsson (2014; also see Botvinick \& Cohen, 1998; Ehrsson et al., 2004; Lloyd, 2007). Results showed that, on average, participants experienced the prosthetic hand as their own hand after synchronous stroking (median $=5$ ) but not after asynchronous stroking (median = 2); similarly, participants attributed the touch they felt to the stroking of the prosthetic hand in the synchronous condition (median $=5$ ) but not in the asynchronous condition (median $=2$ ). A Wilcoxon signed rank test showed that these medians were significantly different $(z=-5.91$ and $z=-4.96$ respectively, $p s<0.001)$ indicating that we successfully induced the RHI in the synchronous stroking condition.

To test our main hypothesis, we conducted a marginal multilevel model analysis in SPSS (version 22), employing restricted maximum likelihood criteria. Specifically, we entered SCC (mean-centered across all participants), stimulation condition (repeated measures factor) and their interaction as predictors of embodiment. We included the interaction between SCC and condition as this enabled us to examine the effect of SCC on embodiment in the asynchronous condition while also including the synchronous condition in the model. Because our main hypothesis was about asynchronous stroking, we dummy-coded stimulation condition so that the 
asynchronous condition was the reference category (i.e., asynchronous $=0$ ); thus, the intercept in the model represents the degree of embodiment for the average person in the asynchronous condition. Due to the presence of the interaction term, the coefficient for SCC in our model represents the effect of SCC on embodiment during asynchronous stroking - the key test of our main hypothesis about SCC.

Results showed a significant effect of stimulation condition, $b=1.25, t(78)=7.94, p<$ $.001,95 \%$ CI $[0.93,1.56]$, indicating that participants were more likely to embody the prosthetic hand in the synchronous (vs. asynchronous) stimulation condition, consistent with the Wilcoxon signed rank test and prior research (Botvinick \& Cohen, 1998; Ehrsson, Spence, \& Passingham, 2004; Ehrsson, Holmes, \& Passingham, 2005; Lloyd, 2007). Critically, as predicted, results revealed a significant effect of SCC, $b=-0.34, t(78)=-2.32, p=.023,95 \%$ CI $[-0.64,-0.05]$, indicating that people with an unclear and unstable sense of self were more likely to embody the prosthetic in the asynchronous stroking condition, when the effect is unwarranted. Finally, results showed no significant interaction between SCC and condition $(b=0.21, t(78)=1.25, p=$ $.214,95 \%$ CI $[-0.13,0.55])$. Although we had no predictions about the interaction, this result suggests that the association between SCC and embodiment was similar in the two conditions. For the sake of completeness, we examined the effect of SCC in the synchronous condition; the direction of the effect was the same as in the asynchronous condition, with those lower in SCC being more likely to embody the prosthetic hand, but the effect of SCC on embodiment in the synchronous condition was not significant $(b=-0.13, t(78)=-0.65, p=.52$, 95\% CI [ -0.52 , 0.27]). We suspect that this null effect is likely because of the robustness of the RHI. That is, during synchronous stroking, most people—-both those low and high in SCC—experience a strong RHI. Results are summarized in Table 1 and depicted in Figure 1. 
Table 1. Results of multilevel model analysis predicting embodiment of the prosthetic hand.

\begin{tabular}{llll}
\hline Predictor & $b$ & $95 \%$ Confidence Interval & $t(78)$
\end{tabular}

\begin{tabular}{lccc}
\hline Intercept & $2.59^{* * *}$ & $2.33,2.86$ & 19.50 \\
\hline Stimulation condition & $1.25^{* * *}$ & $0.93,1.56$ & 7.94 \\
\hline SCC & $-0.34^{*}$ & $-0.64,-0.05$ & -2.32 \\
\hline SCC $\times$ Stimulation Condition & 0.21 & $-0.13,0.55$ & 1.25 \\
\hline${ }^{*} p<.05 ; * * * p<.001$ & & &
\end{tabular}

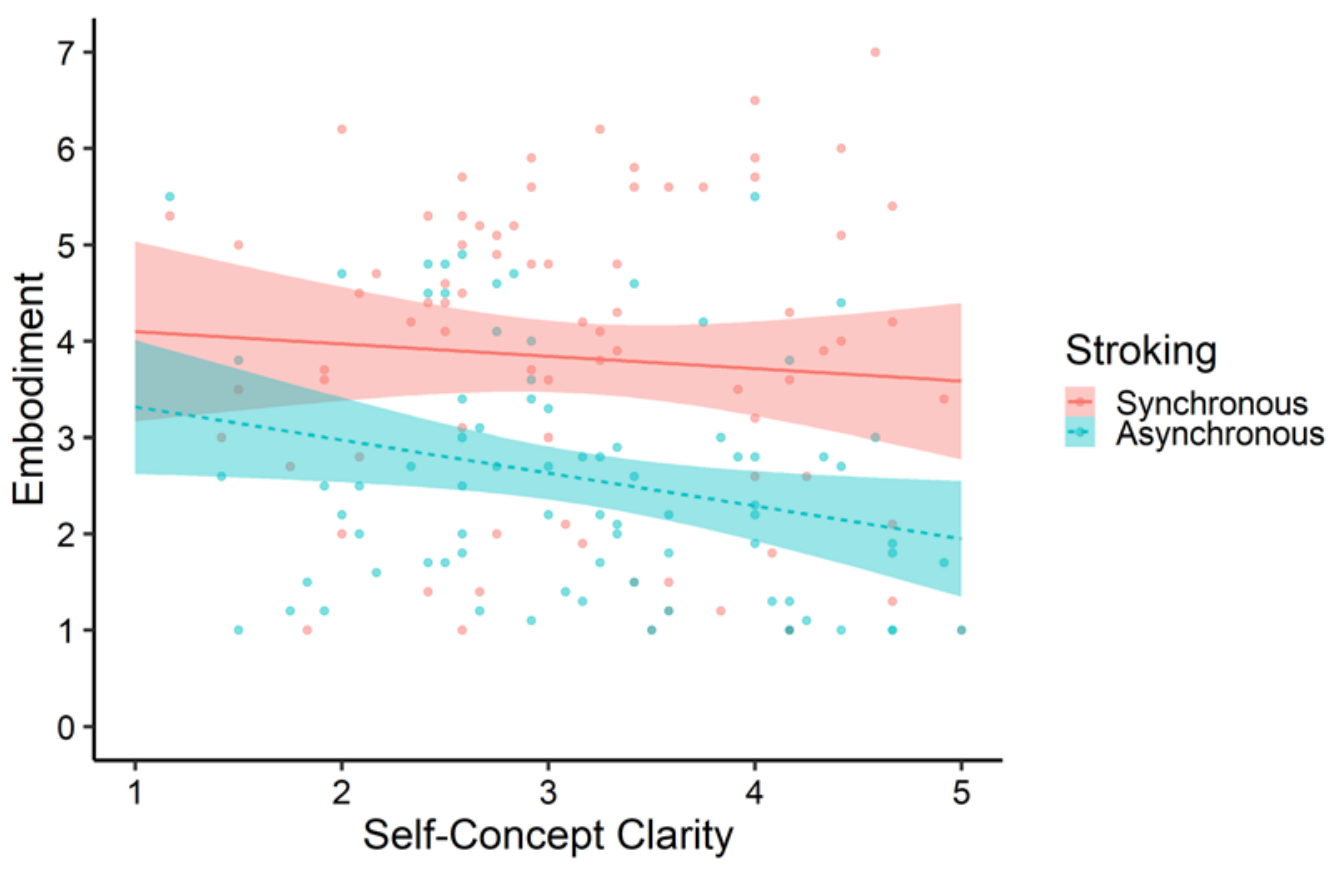

Figure 1. The relationship between self-concept clarity and embodiment. Self-concept clarity significantly predicts embodiment of the prosthetic hand in the asynchronous stimulation condition. Shaded areas represent 95\% confidence bands. 


\section{Study 2}

In Study 1, we showed that low SCC is associated with greater susceptibility to the RHI when there is no sensory conflict between visual and tactile inputs to be resolved, suggesting that individuals who have an unclear sense of self also have a more malleable bodily self. The RHI, however, involves experiencing illusory ownership over a single body part (i.e., a hand) and hence assesses malleability of body-part ownership, rather than malleability of whole-body ownership. Given that the bodily self is experienced as a single, coherent whole-body representation, rather than the sum of multiple representations of separate body parts (Metzinger, 2004), assessing susceptibility to whole-body ownership would more completely capture malleability of the bodily self. To address this, in Study 2, we sought to conceptually replicate and extend our findings by testing if low SCC people are also more vulnerable to the body-swap illusion, that is, the impression that one possesses another person's entire body (Petkova \& Ehrsson, 2008). To this end, we took advantage of a study investigating whether experiencing the body-swap illusion with a different race target reduces prejudice (Thériault et al., in preparation). Specifically, participants in the body-swap condition were outfitted with a virtualreality head-mounted display, which gave them a first-person perspective from the body of another person —an important determinant of body ownership (Ehrsson, 2007). The body-swap illusion was elicited by instructing participants to execute a series of movements in synchrony with the other person. Based on our findings in Study 1, we predicted that those low in SCC would be more susceptible to the body-swap illusion. 


\section{Methods}

\section{Participants}

As noted, for Study 2, we drew upon a larger study examining the effects of different perspective-taking manipulations on racism toward Black individuals (Thériault et al., in preparation). Specifically, we analyzed data from the 34 participants randomly assigned to the body-swap condition. There were 25 women and nine men; participants ranged in age from 1831 years old $(M=22.26, S D=3.35)$. Of note, although the larger study analyzed only non-Black participants, two participants in the body-swap condition were Black; because we did not have specific predictions about race, we elected to include these participants (although the pattern of results reported below does not change if these participants are excluded). The procedures were approved by the Integrated Health and Social Services University Network for West-Central Montreal Institutional Review Board and participants were compensated \$20.

Because we drew upon an existing dataset we could not base our sample size on our effect of interest; however, results from a post-hoc sensitivity power analysis indicate that this sample size was sensitive to detect correlations of $r=.45$ with $80 \%$ power. Given that this correlation represents a moderate to large effect (Cohen, 1988), this estimate suggests that our study was well-powered to test the association between SCC and susceptibility to the body-swap illusion.

\section{Procedure}

The experimenter first met participants and a gender-matched Black confederate at the building lobby and guided them to the testing location. Participants were informed that they would be participating in a study examining the influence of immersive virtual technology and 
embodiment on social cognition (i.e., they were not explicitly told that they would be seeing the confederate's perspective through a headset). After giving their informed consent, participants and the confederate were instructed to sit on one of two chairs and to put on the virtual reality headset (see below for details). Through the headset, participants received visual input from a camera attached to the head of the confederate (and vice versa for the confederate). That is, looking down at their hands or at the mirror in front of them, participants would see the hands or the reflection of the confederate, rather than their own hands or reflection (see Figure 2). Once the participant and the confederate were wearing the virtual reality headsets, the experimenter read a script giving them instructions to execute a series of movements in order to begin the body-swap induction. Importantly, participants were told that they had been randomly assigned to the "follower" role while the confederate had been assigned to the "leader" role (in fact, participants were always assigned to the "follower” role). The leader's role was to follow the experimenter's instructions, and the follower's role was to synchronize their movements as much as possible with those of the leader. In this way, participants saw the confederate executing movements from a first-hand perspective via the headset as they themselves executed the same movements. After approximately 5 minutes, participants were instructed to close their eyes so that the curtains hiding the mirrors could be removed. Once the curtains were removed, participants opened their eyes and were instructed: "For the next minute, look at yourself in the mirror in front of you”. This was done to strengthen the illusion that the confederate's body belonged to the participant (Preston, Kuper-Smith, \& Ehrsson, 2015). The experimenter then continued with the movement instructions. The body-swapping induction lasted approximately 10 minutes. After this induction, participants completed a self-report measure of embodiment, various tasks and measures unrelated to the current investigation, as well as the Self-Concept 
Clarity scale $(\omega=.93)$ used in Study 1 . Finally, participants were partially debriefed and compensated for their time, and then fully debriefed at a later time. For full procedural details, see (Citation Blinded).

Experimental Setup

Participants sat on a chair facing a large partition that separated the testing area, approximately $125 \mathrm{~cm}$ from the partition. In a parallel setup, the confederate sat on the other side of the partition such that the participant and the confederate could not see each other. Directly in front of the participant and the confederate, against the partition, was a large mirror $(74 \mathrm{~cm} \times 165$ $\mathrm{cm}$ ) covered by a black curtain. The experimenter stood to the right of the participant (left of the confederate) as they delivered the instructions through a headset microphone. A speaker to the left of the participant also transmitted the voice of the experimenter so that the instructions appeared to come from both sides of the participant. This was important to maintain the illusion of body-swapping; otherwise, the participant would see the experimenter on their left during the illusion but hear their voice from the right. 


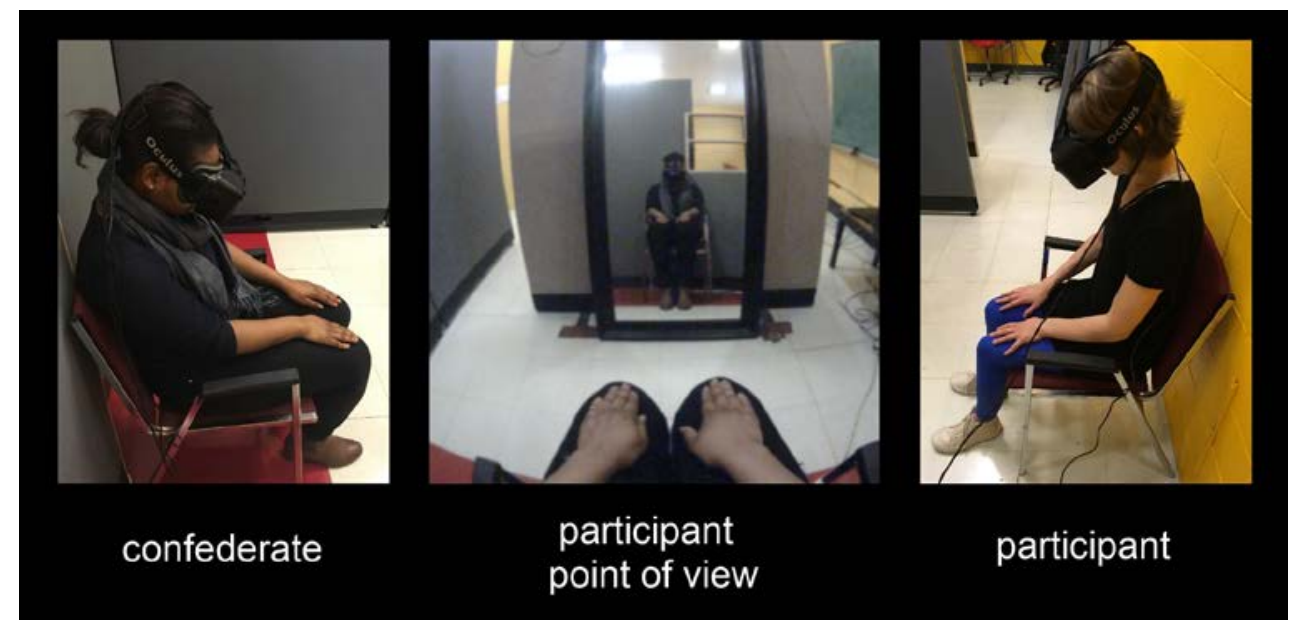

Figure 2. Experimental setup with large partition separating confederate and participant. Left: Confederate looking down at her hands. Middle: Participant point of view (through the virtualreality headset), seeing the confederate's hands and image reflection, instead of her own. Right: Participant looking down at her hands.

Materials and Measures

Virtual Reality Headset. We used the Oculus Rift Development Kit 2 head-mounted display. Two small screens are located inside, with resolutions of $960 \times 1080$ pixels per eye and a refresh rate of 75 frames per second, resulting in horizontal and vertical fields of view of approximately $100^{\circ}$ of visual angle. To allow participants to see the person’s visual perspective, we attached a modified PlayStation 3 camera to the Oculus Rift device using a custom 3D printed structure. The software used to generate the body-swap illusion is called The Machine to 
Be Another, developed by the international and interdisciplinary collective BeAnotherLab (Bertrand, Gonzalez-Franco, Cherene, \& Pointeau, 2014) ${ }^{1}$.

Body-Swap Embodiment Questionnaire $(\omega=.91)$. To assess the degree to which participants experienced the body-swap illusion, we adapted the Longo et al. (2008) embodiment questionnaire used in Study 1. Specifically, using an 8-point scale, participants indicated their level of agreement with 10 items assessing the extent to which they experienced the confederate’s body as their own $(0=$ I do not agree at all and $7=$ I agree completely). Sample items include: "It seemed like the body I saw belonged to me" and "It seemed like the body I saw was my body” (see Table S2 for questionnaire). The strength of the body-swap illusion was operationalized as the mean of all items relating to embodiment, with higher scores indicating a stronger illusion that the confederate's body belonged to the participant.

\section{Results and Discussion}

To test the hypothesis that those low in SCC are more vulnerable to the body-swap illusion, we conducted a linear regression in R version 3.5.1 with SCC predicting embodiment as assessed by our body-swap embodiment questionnaire. As predicted, and conceptually replicating findings from Study 1, SCC was negatively associated with the strength of the bodyswap illusion $(b=-0.48, t(32)=-2.98, p=.006$; 95\% CI [-0.81, -0.15$])$. That is, as shown in Figure 3, individuals with an unclear sense of self reported experiencing the body-swap illusion more strongly than those with a more clear sense of self.

\footnotetext{
${ }^{1}$ This software is publicly available at: https://github.com/BeAnotherLab/The-Machine-to-be-Another.
} 




Figure 3. The relationship between self-concept clarity and embodiment in the body-swap illusion. Self-concept clarity significantly predicts embodiment of the other person's body. Shaded area represents 95\% confidence band.

\section{General Discussion}

In the present studies, we examined the relationship between the self-concept, the cognitive representation of everything that can be described as “me” or "mine” (Markus, 1977), and the bodily self, the implicit, pre-reflective awareness of the perceptual experiences of one’s

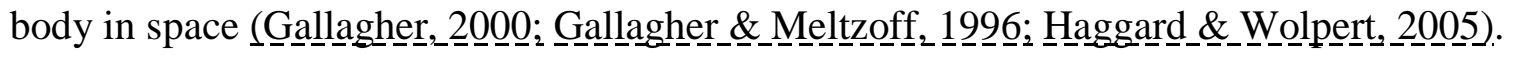
Specifically, we investigated whether clarity and stability in the self-concept is associated with clarity and stability in the bodily self. In Study 1, we used the RHI paradigm to assess whether 
lower SCC individuals are more vulnerable to misperceiving sensory cues and incorporating that irrelevant information into their bodily self. As predicted, those low (vs. high) in SCC reported more embodiment of the prosthetic hand during asynchronous stroking — that is, the control condition which typically does not give rise to the illusion because there is less sensory conflict between what is "me” and "not me”. We suspect that low SCC individuals have such a tenuous and fragile sense of self that they incorporate the prosthetic hand into their own body representation even in this inappropriate context when sensory signals do not warrant it. Interestingly, a similar finding — susceptibility to the RHI under asynchronous stimulation—was observed in patients with schizophrenia (Thakkar, Nichols, McIntosh, \& Park, 2011), a disorder characterized by disturbances in self-processing including self-concept confusion (for review, see_Cicero ${ }_{2}$ 2017). In Study 2, we conceptually replicate this effect by demonstrating that low SCC individuals are also more susceptible to the body-swap illusion-i.e., experiencing another person's body as their own. This observation is notable given that the confederate in the bodyswap illusion was of a different race than almost all participants, a factor known to reliably decrease the strength of bodily illusions (Farmer et al., 2012; Lira et al., 2017). Taken together, our results show that a weak and unclear sense of self is associated with an excessively malleable bodily self. While previous work has observed an association between SCC and body image (i.e.,

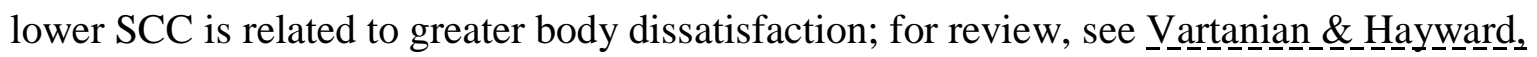
2017), to our knowledge, this is the first evidence linking SCC to the bodily self.

Our findings are correlational and an important question for future work is to test the causal relations between SCC and body malleability. Consistent with the notion that the self "starts with the body" (Baumeister, 1992), it is possible that our bodily self contributes to the clarity of our self-concept in a bottom-up fashion. Having a more malleable representation of 
one’s own body may predispose one to question one’s psychological experience, which could ultimately lead to an unclear self-concept. In fact, as noted, developmentally, the bodily self comes online prior to the development of the self-concept or identity: infants exhibit evidence of bodily awareness as manifested by, for example, recognizing themselves in a mirror (Amsterdam, 1972; Lewis \& Brooks-Gunn, 1979) before the development of a self-concept or personal identity (Damon \& Hart, 1982; Stipek, Gralinski, \& Kopp, 1990). Alternatively, having a weak and unclear sense of self may make people more susceptible to alterations in their bodily representations. This notion is consistent with findings showing that increasing awareness of the self-concept translates to improved awareness of internal bodily signals such as heartbeat (Ainley, Maister, Brokfeld, Farmer, \& Tsakiris; 2013). To examine if SCC plays a causal role in

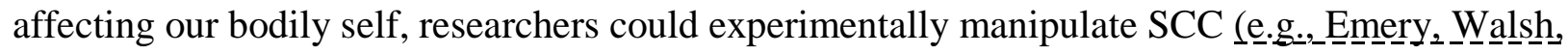
\& Slotter, 2015) before exposing participants to a bodily illusion. A third possibility is that rather than being unidirectional, the self-concept and bodily self may interact in a dynamic reciprocal fashion to form a clear and coherent sense of self (Brandon, 2016). For example, low SCC individuals’ proclivity to incorporate inappropriate and unwarranted bodily information into the self may lead to a vicious cycle by which self-concept confusion is maintained, or even exacerbated. Future research is needed to elucidate the precise nature of the relationship between SCC and body malleability.

Our research may have important implications for interpersonal processes. Social interaction requires processing information about the other person’s internal state- their thoughts, feelings, motivations, attitudes. Interestingly, compelling evidence shows that processing others' internal states activates the same neural representations as when the self experiences these internal states (Bernhardt \&_Singer,_2012; Gallagher_et_al._.2000). Such 
“mirroring” can result in potential conflicts between representations of the other and the self, and thus successful social interaction requires self-other distinction: the ability to differentiate between one’s own experiences and the experiences of the other (see Guzman, Bird, Banissy, \& Catmur, 2016 and Steinbeis, 2016 for reviews). For example, the control of our automatic tendency to imitate others requires the ability to distinguish between one's own motor plan and that of the other (Wang \& Hamilton, 2012). Perspective-taking requires appreciating differences between one's own mental state and that of the other to avoid simply attributing one's own perspective to the other person, especially when the other's perspective conflicts with one's own (Santiesteban et al., 2012). Finally, when empathizing with another, the degree of differentiation between the self and other may lead to qualitatively different empathic reactions. As Batson (1987) argued, failing to maintain adequate boundaries between one's own emotions and those of another person can result in empathic personal distress, a self-oriented, aversive response that often detracts from helping the person in need (Batson, 1987). By contrast, empathic concern, an other-oriented response that induces a desire to alleviate the other's suffering, is associated with greater self-other distinction (Batson et al., 1997). Low SCC individuals’ difficulties with bodily self-other distinction (i.e., excessively malleable bodily self) may predispose them to troubles with social processes such as the ones described above. Future work could investigate this idea.

This research may also have implications for understanding clinical conditions marked by difficulties with self-representations. In particular, our findings suggest that disorders characterized by disturbances in one aspect of the self may also be characterized by disturbances in other aspects of the self. As noted, individuals with schizophrenia, like those with low SCC,


interestingly, schizophrenia has been shown to be related to low SCC (Cicero, 2017). Together, 
these findings suggest that people with schizophrenia are characterized by a lack of stability in both the self-concept and bodily self. Beyond schizophrenia, one defining feature of borderline personality disorder (BPD) is "markedly and persistently unstable self-image or sense of self” (American Psychiatric Association, 2013); our findings suggest that these patients may also experience unstable bodily representations. Indeed, an unclear bodily self may explain why BPD patients tend to experience depersonalization (Brodsky, Cloitre, \& Dulit, 1995), a feeling of separation between oneself and one's body. Bodily malleability could also explain BPD individuals' tendency to excessively merge with others (Beeney, Hallquist, Ellison, \& Levy, 2016). Moving away from disorders of the self-concept, a condition known to be associated with disturbances in the bodily self is mirror-touch synesthesia: when observing another person being touched, mirror-touch synesthetes experience tactile stimulation on the congruent part of their own body, suggesting that their bodily representations are highly malleable (Banissy \& Ward, 2007). If bodily malleability is related to an unclear and unstable cognitive self, mirror-touch synesthetes should also be vulnerable to self-concept confusion. Interestingly, anecdotal evidence suggests that mirror-touch synesthetes also have a tenuous self-concept; as one woman with this condition described, "I spent my life losing myself in other people, on whims, just gone” and “I just have no idea who I am” (Spiegel \& Miller, 2015). Her comments resonate with research indicating that individuals low in SCC search for external sources of self-definition (Campbell, 1990). Given research showing that higher SCC is associated with better relationships (e.g., Lewandowski, Nardone, \& Raines, 2009) and well-being (Campbell et al., 1996; Treadgold, 1999), our findings imply that mirror-touch synesthetes may be prone to relationship difficulties and lower well-being. Future work should examine if people with one 
kind of self disturbance-either in the self-concept or the bodily self_-also experience disturbances in the other aspects of the self.

A few limitations should be noted. Because the body-swap illusion is a resource-intensive procedure, we drew upon a larger study using this paradigm to test our hypothesis that SCC is associated with this bodily illusion; consequently, we could not base our sample size on the effect we were interested in investigating. That said, the purpose of Study 2 was to conceptually replicate the findings from Study 1, and to test whether the SCC-body malleability association extends to the entire body. Moreover, a post-hoc sensitivity analysis indicated that our sample size was sensitive to detecting the observed moderate- to large-sized effect of SCC in this study. Nonetheless, future work should replicate the association between SCC and susceptibility to the body-swap illusion in a larger sample to ascertain the robustness of the effect. We also did not have an explicit asynchronous movement condition in Study 2. However, two features of the body-swap paradigm we used likely attenuated the sensory conflict in the body-swap illusion. First, although the participants and confederate were instructed to move in synchrony in the body-swap paradigm, this was difficult to achieve in practice. As a result, the movements between participants and the confederate were likely somewhat asynchronous, similar to the asynchronous stimulation condition in the RHI paradigm. Second, with the exception of two participants, the participant and confederate were of different races, a factor known to attenuate degree of embodiment (Farmer et al., 2012; Lira et al., 2017). Again, though, future work should examine the specificity of the relationship between SCC and susceptibility to body-swapping by including a condition where participants are explicitly instructed to move out of synchrony with the confederate. 
In conclusion, few topics are as central to human existence as the self. Questions like “Where does our sense of self come from?” and “How do we maintain a clear, stable, unitary sense of self?” have fascinated psychologists and philosophers for centuries. To answer these fundamental questions, some researchers have focused on the self-concept while others have examined the bodily self. Although traditionally investigated separately, both theory and some evidence suggest that these two notions of self are interrelated (Ainley et al., 2013; Banakou et al., 2013; Gallagher, 2000). We add to this literature by demonstrating that low clarity, coherence and stability of the self-concept is associated with susceptibility to bodily illusions. This finding implies that a clear and coherent sense of self entails clarity and coherence in both the psychological and bodily notion of self, suggesting that these notions may represent two sides of the same self. 


\section{Contributions}

The study concept and designs were developed by S. A. Krol and J. A. Bartz for Study 1 and by R. Thériault, J. A. Olson, A. Raz, and S. A. Krol for Study 2. Testing and data collection was performed by S. A. Krol (Study 1) and R. Thériault (Study 2). S. A. Krol performed the data analyses for Study 1 and S. A. Krol and J. A. Bartz performed interpretation for Study 1. R. Thériault performed the data analyses for Study 2 and R. Thériault and S. A. Krol performed interpretation for Study 2. S. A. Krol drafted the manuscript, and R. Thériault, J. A. Olson, and J. A. Bartz provided critical revisions.

\section{Acknowledgements}

We thank Jean-Philippe Gagné, Amanda Dennie, Lauriol Djehounke, Emily Light, and Camille W. Chamberlain for their assistance with data collection. This research was supported by a grant from the Natural Sciences and Engineering Research Council of Canada awarded to J.

A. Bartz, and grants from the Canada Research Chair program, Discovery and Discovery Acceleration Supplement grants from NSERC, and the Canadian Institutes of Health Research to A. Raz. S. A. Krol was supported by a Vanier Canada Graduate Scholarship; and R. Thériault and J. A. Olson were both supported by the Joseph-Armand Bombardier Canada Graduate Scholarship from the Social Sciences and Humanities Research Council of Canada.

\section{Declaration of Conflicting Interests}

The authors declare no conflicting interests.

\section{Availability of Materials and Data}

Researchers interested in accessing the study materials and data should contact the corresponding author. 


\section{References}

Abdulkarim, Z., \& Ehrsson, H. H. (2016). No causal link between changes in hand position sense and feeling of limb ownership in the rubber hand illusion. Attention, Perception \& Psychophysics, 78(2), 707-720. https://doi.org/10.3758/s13414-015-1016-0

Ainley, V., Maister, L., Brokfeld, J., Farmer, H., \& Tsakiris, M. (2013). More of myself: Manipulating interoceptive awareness by heightened attention to bodily and narrative aspects of the self. Consciousness and Cognition, 22(4), 1231-1238.

https://doi.org/10.1016/j.concog.2013.08.004

Armel, K. C., \& Ramachandran, V. S. (2003). Projecting sensations to external objects: Evidence from skin conductance response. Proceedings of the Royal Society of London B: Biological Sciences, 270(1523), 1499-1506. https://doi.org/10.1098/rspb.2003.2364

Aron, A., Aron, E. N., Tudor, M., \& Nelson, G. (1991). Close relationships as including other in the self. Journal of Personality and Social Psychology, 60(2), 241-253. https://doi.org/10.1037/0022-3514.60.2.241

Asai, T., Mao, Z., Sugimori, E., \& Tanno, Y. (2011). Rubber hand illusion, empathy, and schizotypal experiences in terms of self-other representations. Consciousness and Cognition, 20(4), 1744-1750. https://doi.org/10.1016/j.concog.2011.02.005

Banakou, D., Groten, R., \& Slater, M. (2013). Illusory ownership of a virtual child body causes overestimation of object sizes and implicit attitude changes. Proceedings of the National Academy of Sciences of the United States of America, 110(31), 12846-12851. https://doi.org/10.1073/pnas.1306779110

Banissy, M. J., \& Ward, J. (2007). Mirror-touch synesthesia is linked with empathy. Nature Neuroscience, 10(7), 815-816. https://doi.org/10.1038/nn1926 
Bassolino, M., Franza, M., Bello Ruiz, J., Pinardi, M., Schmidlin, T., Stephan, M. A., ... Blanke, O. (2018). Non-invasive brain stimulation of motor cortex induces embodiment when integrated with virtual reality feedback. The European Journal of Neuroscience, 47(7), 790-799. https://doi.org/10.1111/ejn.13871

Batson, C. D. (1987). Prosocial Motivation: Is it ever Truly Altruistic? In Leonard Berkowitz (Ed.), Advances in Experimental Social Psychology: Vol. Volume 20 (pp. 65-122). Retrieved from http://www.sciencedirect.com/science/article/pii/S0065260108604128

Batson, C. D., Sager, K., Garst, E., Kang, M., Rubchinsky, K., \& Dawson, K. (1997). Is empathy-induced helping due to self-other merging? Journal of Personality and Social Psychology, 73(3), 495.

Baumeister R. The nature and structure of the self: An overview. In: Baumeister R., editor. The self in social psychology. Philadelphia, PA: Psychology Press; 1999. pp. 1-21.

Beeney, J. E., Hallquist, M. N., Ellison, W. D., \& Levy, K. N. (2016). Self-other disturbance in borderline personality disorder: Neural, self-report and performance-based evidence. Personality Disorders, 7(1), 28-39. https://doi.org/10.1037/per0000127

Bergouignan, L., Nyberg, L., \& Ehrsson, H. H. (2014). Out-of-body-induced hippocampal amnesia. Proceedings of the National Academy of Sciences, 111(12), 4421-4426. https://doi.org/10.1073/pnas.1318801111

Bernhardt, B. C., \& Singer, T. (2012). The Neural Basis of Empathy. Annual Review of Neuroscience, 35(1), 1-23. https://doi.org/10.1146/annurev-neuro-062111-150536

Botvinick, M., \& Cohen, J. (1998). Rubber hands’ feel’touch that eyes see. Nature, 391(6669), 756-756. 
Brandon, P. (2016). Body and self: An entangled narrative. Phenomenology and the Cognitive Sciences, 15(1), 67-83. https://doi.org/10.1007/s11097-014-9369-8

Brodsky, B. S., Cloitre, M., \& Dulit, R. A. (1995). Relationship of dissociation to self-mutilation and childhood abuse in borderline personality disorder. The American Journal of Psychiatry, 152(12), 1788-1792. https://doi.org/10.1176/ajp.152.12.1788

Campbell, J. D. (1990). Self-esteem and clarity of the self-concept. Journal of Personality and Social Psychology, 59(3), 538-549.

Campbell, Jennifer D., Trapnell, P. D., Heine, S. J., Katz, I. M., Lavallee, L. F., \& Lehman, D. R. (1996). Self-concept clarity: Measurement, personality correlates, and cultural boundaries. Journal of Personality and Social Psychology, 70(1), 141-156. https://doi.org/10.1037/0022-3514.70.1.141

Cicero, D. C. (2017). Self-Concept Clarity and Psychopathology. In J. Lodi-Smith \& K. G. DeMarree (Eds.), Self-Concept Clarity: Perspectives on Assessment, Research, and Applications (pp. 219-242). https://doi.org/10.1007/978-3-319-71547-6_12

Conway, M. A., \& Pleydell-Pearce, C. W. (2000). The construction of autobiographical memories in the self memory system. Psychological Review, 107(2). Retrieved from http://research-information.bristol.ac.uk/en/publications/the-construction-ofautobiographical-memories-in-the-self-memory-system(9e76b143-9786-4880-a9a437a80f809df2)/export.html

Cuperman, R., Robinson, R. L., \& Ickes, W. (2014). On the Malleability of Self-image in Individuals with a Weak Sense of Self. Self and Identity, 13(1), 1-23. https://doi.org/10.1080/15298868.2012.726764 
Damon, W., \& Hart, D. (1982). The Development of Self-Understanding from Infancy Through Adolescence. Child Development, 53(4), 841-864. https://doi.org/10.2307/1129122

Ehrsson, H. H. (2007). The Experimental Induction of Out-of-Body Experiences. Science, 317(5841), 1048-1048. https://doi.org/10.1126/science.1142175

Ehrsson, H. H. (2012). The concept of body ownership and its relation to multisensory integration. The New Handbook of Multisensory Processes, 775-792.

Ehrsson, H. H., Holmes, N. P., \& Passingham, R. E. (2005). Touching a rubber hand: Feeling of body ownership is associated with activity in multisensory brain areas. The Journal of Neuroscience : The Official Journal of the Society for Neuroscience, 25(45), 1056410573. https://doi.org/10.1523/JNEUROSCI.0800-05.2005

Ehrsson, H. H., Rosén, B., Stockselius, A., Ragnö, C., Köhler, P., \& Lundborg, G. (2008). Upper limb amputees can be induced to experience a rubber hand as their own. Brain, 131(12), 3443-3452. https://doi.org/10.1093/brain/awn297

Ehrsson, H. H., Spence, C., \& Passingham, R. E. (2004). That's my hand! Activity in premotor cortex reflects feeling of ownership of a limb. Science (New York, N.Y.), 305(5685), 875877. https://doi.org/10.1126/science.1097011

Emery, L. F., Walsh, C., \& Slotter, E. B. (2015). Knowing Who You Are and Adding to It Reduced Self-Concept Clarity Predicts Reduced Self-Expansion. Social Psychological and Personality Science, 6(3), 259-266. https://doi.org/10.1177/1948550614555029

Eshkevari, E., Rieger, E., Longo, M. R., Haggard, P., \& Treasure, J. (2012). Increased plasticity of the bodily self in eating disorders. Psychological Medicine, 42(4), 819-828. https://doi.org/10.1017/S0033291711002091 
Farmer, H., Tajadura-Jiménez, A., \& Tsakiris, M. (2012). Beyond the colour of my skin: How skin colour affects the sense of body-ownership. Consciousness and Cognition, 21(3), 1242-1256. https://doi.org/10.1016/j.concog.2012.04.011

Fonagy, P., Gergely, G., Jurist, E., \& Target, M. (2002). The Development of an Understanding of Self and Agency. In Affect Regulation, Mentalization, and the Development of the Self. New York: Other Press.

Freud, S. (1961). The ego and the id. New York, NY, US: W W Norton \& Co.

Gallagher, H. L., Happé, F., Brunswick, N., Fletcher, P. C., Frith, U., \& Frith, C. D. (2000). Reading the mind in cartoons and stories: An fMRI study of "theory of mind” in verbal and nonverbal tasks. Neuropsychologia, 38(1), 11-21.

Gallagher, S. (2000). Philosophical conceptions of the self: Implications for cognitive science. Trends in Cognitive Sciences, 4(1), 14-21. https://doi.org/10.1016/S13646613(99)01417-5

Gallagher, S., \& Meltzoff, A. N. (1996). The earliest sense of self and others: Merleau-Ponty and recent developmental studies. Philosophical Psychology, 9(2). https://doi.org/10.1080/09515089608573181

Grynberg, D., \& Pollatos, O. (2015). Alexithymia modulates the experience of the rubber hand illusion. Frontiers in Human Neuroscience, 9. https://doi.org/10.3389/fnhum.2015.00357

Guzman, M. de, Bird, G., Banissy, M. J., \& Catmur, C. (2016). Self-other control processes in social cognition: From imitation to empathy. Phil. Trans. R. Soc. B, 371(1686), 20150079. https://doi.org/10.1098/rstb.2015.0079

Haggard, P., \& Wolpert, D. M. (2005). Disorders of body schema. In H. J. Freund, M. Jeannerod, M. Hallett, \& R. Leiguarda (Eds.), Higher-order motor disorders: from 
neuroanatomy and neurobiology to clinical neurology (pp. 261-271). Retrieved from http://discovery.ucl.ac.uk/182411/

Kalckert, A., \& Ehrsson, H. H. (2012). Moving a Rubber Hand that Feels Like Your Own: A Dissociation of Ownership and Agency. Frontiers in Human Neuroscience, 6, 40. https://doi.org/10.3389/fnhum.2012.00040

Kilteni, K., Maselli, A., Kording, K. P., \& Slater, M. (2015). Over my fake body: Body ownership illusions for studying the multisensory basis of own-body perception. Frontiers in Human Neuroscience, 9, 141. https://doi.org/10.3389/fnhum.2015.00141

Kling, K. C., Ryff, C. D., \& Essex, M. J. (1997). Adaptive Changes in the Self-Concept During a Life Transition Adaptive Changes in the Self-Concept During a Life Transition. Personality and Social Psychology Bulletin, 23(9), 981-990. https://doi.org/10.1177/0146167297239008

Lenggenhager, B., Tadi, T., Metzinger, T., \& Blanke, O. (2007). Video ergo sum: Manipulating bodily self-consciousness. Science (New York, N.Y.), 317(5841), 1096-1099. https://doi.org/10.1126/science.1143439

Lewandowski, G. W., \& Nardone, N. (2012). Self-concept Clarity’s Role in Self-Other Agreement and the Accuracy of Behavioral Prediction. Self and Identity, 11(1), 71-89. https://doi.org/10.1080/15298868.2010.512133

Lewandowski, G. W., Nardone, N., \& Raines, A. J. (2010). The Role of Self-concept Clarity in Relationship Quality. Self and Identity, 9(4), 416-433. https://doi.org/10.1080/15298860903332191 
Lira, M., Egito, J. H., Dall’Agnol, P. A., Amodio, D. M., Gonçalves, Ó. F., \& Boggio, P. S. (2017). The influence of skin colour on the experience of ownership in the rubber hand illusion. Scientific Reports, 7(1), 15745. https://doi.org/10.1038/s41598-017-16137-3

Lodi-Smith, J., \& DeMarree, K. G. (Eds.). (2017). Self-Concept Clarity: Perspectives on Assessment, Research, and Application (1st ed.). https://doi.org/10.1007/978-3-31971547-6

Longo, M. R., Schüür, F., Kammers, M. P. M., Tsakiris, M., \& Haggard, P. (2008). What is embodiment? A psychometric approach. Cognition, 107(3), 978-998. https://doi.org/10.1016/j.cognition.2007.12.004

Maister, L., Sebanz, N., Knoblich, G., \& Tsakiris, M. (2013). Experiencing ownership over a dark-skinned body reduces implicit racial bias. Cognition, 128(2), 170-178. https://doi.org/10.1016/j.cognition.2013.04.002

Markus, H, \& Wurf, E. (1987). The Dynamic Self-Concept: A Social Psychological Perspective. Annual Review of Psychology, 38(1), 299-337. https://doi.org/10.1146/annurev.ps.38.020187.001503

Markus, Hazel. (1977). Self-schemata and processing information about the self. Journal of Personality and Social Psychology, 35(2), 63-78. https://doi.org/10.1037/00223514.35.2.63

Marotta, A., Tinazzi, M., Cavedini, C., Zampini, M., \& Fiorio, M. (2016). Individual Differences in the Rubber Hand Illusion Are Related to Sensory Suggestibility. PLOS ONE, 11(12), e0168489. https://doi.org/10.1371/journal.pone.0168489 
Mashek, D. J., Aron, A., \& Boncimino, M. (2003). Confusions of Self With Close Others. Personality and Social Psychology Bulletin, 29(3), 382-392. https://doi.org/10.1177/0146167202250220

Meltzoff, A. N., \& Moore, M. K. (1983). Newborn infants imitate adult facial gestures. Child Development, 54(3), 702-709.

Metzinger, T. (2004). Being No One: The Self-Model Theory of Subjectivity. MIT Press.

Neisser, U. (1997). The Roots of Self-Knowledge: Perceiving Self, It, and Thoua. Annals of the New York Academy of Sciences, 818(1), 19-33. https://doi.org/10.1111/j.17496632.1997.tb48243.x

Petkova, V. I., \& Ehrsson, H. H. (2008). If I Were You: Perceptual Illusion of Body Swapping. PLOS ONE, 3(12), e3832. https://doi.org/10.1371/journal.pone.0003832

Petkova, V. I., \& Ehrsson, H. H. (2009). When Right Feels Left: Referral of Touch and Ownership between the Hands. PLOS ONE, 4(9), e6933. https://doi.org/10.1371/journal.pone.0006933

Preston, C., Kuper-Smith, B. J., \& Ehrsson, H. H. (2015). Owning the body in the mirror: The effect of visual perspective and mirror view on the full-body illusion. Scientific Reports, 5, 18345. https://doi.org/10.1038/srep18345

Santiesteban, I., White, S., Cook, J., Gilbert, S. J., Heyes, C., \& Bird, G. (2012). Training social cognition: From imitation to Theory of Mind. Cognition, 122(2), 228-235. https://doi.org/10.1016/j.cognition.2011.11.004

Schacter, D. L., Chiao, J. Y., \& Mitchell, J. P. (2003). The seven sins of memory: Implications for self. Annals of the New York Academy of Sciences, 1001, 226-239. 
Sforza, A., Bufalari, I., Haggard, P., \& Aglioti, S. M. (2010). My face in yours: Visuo-tactile facial stimulation influences sense of identity. Social Neuroscience, 5(2), 148-162. https://doi.org/10.1080/17470910903205503

Shimada, S., Fukuda, K., \& Hiraki, K. (2009). Rubber Hand Illusion under Delayed Visual Feedback. PLOS ONE, 4(7), e6185. https://doi.org/10.1371/journal.pone.0006185

Steinbeis, N. (2016). The role of self-other distinction in understanding others' mental and emotional states: Neurocognitive mechanisms in children and adults. Philosophical Transactions of the Royal Society B: Biological Sciences, 371(1686). https://doi.org/10.1098/rstb.2015.0074

Stipek, D. J., Gralinski, J. H., \& Kopp, C. B. (1990). Self-concept development in the toddler years. Developmental Psychology, 26(6), 972-977. https://doi.org/10.1037/00121649.26.6.972

Swann, W. B., \& Read, S. J. (1981a). Acquiring self-knowledge: The search for feedback that fits. Journal of Personality and Social Psychology, 41(6), 1119-1128. https://doi.org/10.1037/0022-3514.41.6.1119

Swann, W. B., \& Read, S. J. (1981b). Self-verification processes: How we sustain our selfconceptions. Journal of Experimental Social Psychology, 17(4), 351-372. https://doi.org/10.1016/0022-1031(81)90043-3

Tajadura-Jiménez, A., Grehl, S., \& Tsakiris, M. (2012). The Other in Me: Interpersonal Multisensory Stimulation Changes the Mental Representation of the Self. PLoS ONE, 7(7), e40682. https://doi.org/10.1371/journal.pone.0040682

Thakkar, K. N., Nichols, H. S., McIntosh, L. G., \& Park, S. (2011). Disturbances in Body Ownership in Schizophrenia: Evidence from the Rubber Hand Illusion and Case Study of 
a Spontaneous Out-of-Body Experience. PLoS ONE, 6(10), e27089. https://doi.org/10.1371/journal.pone.0027089

Thériault, R., Olson, A. J., Krol, S., \& Raz, A. (in preparation, 2019). Embodying the other: Virtual-reality-based body-swapping boosts empathy.

Treadgold, R. (1999). Transcendent Vocations: Their Relationship to Stress, Depression, and Clarity of Self-Concept. Journal of Humanistic Psychology, 39(1), 81-105. https://doi.org/10.1177/0022167899391010

Tsakiris, M. (2010). My body in the brain: A neurocognitive model of body-ownership. Neuropsychologia, 48(3), 703-712. https://doi.org/10.1016/j.neuropsychologia.2009.09.034

Tsakiris, M., \& Haggard, P. (2005). The rubber hand illusion revisited: Visuotactile integration and self-attribution. Journal of Experimental Psychology. Human Perception and Performance, 31(1), 80-91. https://doi.org/10.1037/0096-1523.31.1.80

Tsakiris, M., Jiménez, A. T.-, \& Costantini, M. (2011). Just a heartbeat away from one’s body: Interoceptive sensitivity predicts malleability of body-representations. Proceedings of the Royal Society of London B: Biological Sciences, 278(1717), 2470-2476. https://doi.org/10.1098/rspb.2010.2547

Vartanian, L. R., \& Hayward, L. E. (2017). Self-Concept Clarity and Body Dissatisfaction. In J. Lodi-Smith \& K. G. DeMarree (Eds.), Self-Concept Clarity: Perspectives on Assessment, Research, and Applications (pp. 195-218). https://doi.org/10.1007/978-3-319-715476_11 
Wang, Y., \& Hamilton, A. F. de C. (2012). Social top-down response modulation (STORM): A model of the control of mimicry in social interaction. Frontiers in Human Neuroscience, 6. https://doi.org/10.3389/fnhum.2012.00153 